\title{
The Medicinal Efficacies of Cordyceps Militaris (L.) Link
}

\begin{tabular}{l|c|}
\cline { 2 - 2 } & $\begin{array}{c}\text { Mini Review } \\
\text { Volume 1 Issue } 2\end{array}$ \\
Wu TF* & $\begin{array}{c}\text { Received Date: November 26, 2016 } \\
\text { Published Date: November 30, 2016 } \\
\text { Taiwan }\end{array}$ \\
DoI: 10.23880/oajmb-16000110
\end{tabular}

*Corresponding author: Ting Feng Wu, PhD in Microbiology, Department of Biotechnology, Southern Taiwan University of Science and Technology, Taiwan, Tel:+886-6-2533131 ext. 8394; Email: wutingfe@stust.edu.tw

\section{Abstract}

Cordyceps militaris is the representative species of Ascomycete genus Cordyceps and can be found throughout most of the Northern Hemisphere as a pathogen of lepidopteran insect pupae. Mycelia or fruit bodies of C.militaris, traditionally used as an herbal cure and a tonic food in East Asia, are studied in the West recently because of its various pharmacological capabilities. Various types of extracts prepared from mycelia or bodies of $C$. militaris are found to exhibit a variety of anticancer efficacies in colon cancer, lung cancer and skin cancer etc. Besides, C. militaris extracts are found to exhibit active alleviation toward type I hypersensitivity, so called allergy, in activated mast cells and irritated mice. They are also shown to ameliorate the inflammatory responses in evoked cells and mice. The mycelia or bodies of $C$. militaris may confer a complementary/integrative resource to cure or prevent allergy or tumors.

Keywords: Cordyceps militaris; type I hypersensitivity; allergy; cancer

\section{Introduction}

Cordyceps militaris is the representative species of Ascomycete genus Cordyceps and can be found throughout most of the Northern Hemisphere as a pathogen of lepidopteran insect pupae [1]. C. militaris is easily recognized by the sexual fruit bodies protruding from the inside of fungi-infected lepidopteran insect pupae. The fruit body structure gives the fungus its common name of 'pupa grass' in China and Taiwan. The sexual fruit bodies of C. militaris and C.sinensis are well-known for being used as a traditional Chinese medicine. In recent years, this ancient eastern elixir is getting more attention from western researchers and clinic practitioners as a research topic and an alternative way of medication respectively [2].

\section{Anti-cancer activities}

C. militaris has been investigated for its various pharmacological activities. Various kinds of extracts prepared from C. militaris mycelia or fruit bodies are found to exhibit a variety of anti-cancer efficacies based upon the cell-based or animal models. Mollah et al. (2012) showed that butanol extract of $C$. militaris mycelia grown on germinated soybean evokes $\mathrm{G}_{2} / \mathrm{M}$ cell cycle arrest of human colon cancer HT-29 cells through down-regulation of cycl in B1 and cdc25c [3]. Results collected from the examination of water extract of C. militaris mycelia indicate that the extract treatment can induce death receptor- and mitochondria-mediated apoptosis in lung carcinoma A549 cell via up-regulation of $\mathrm{Bax} / \mathrm{Bcl}-2$ ratio and caspase-8/caspase- 3 activation and also can diminish telomerase activity [4]. Using cell and xenografted animal model, Park et al. (2009) showed that treatment of the extract prepared from silkworm pupae grown C. militaris 
fruit bodies can inhibit VEGF-A and -B synthesis in human MM cells [5], suggesting that the extract incubation can retard angiogenesis. Angiogenesis inhibition is related to GSK $3 \alpha / 3 \beta$, PI3K and Akt1. They also demonstrate that treatment with $C$. militaris extract can inhibit growth of subcutaneously xenografted melanomas.

\section{Anti-allergy and anti- inflammationactivities}

A previous finding has showed that the ethylacetate (EtOAc) layer of methanol extract of germinated soybean grown Cordyceps militar is fruit bodies (GSCM) can inhibit both the $\beta$-hexosaminidase release (degranulation marker) in activated mast cells and the signaling pathway evoked by FceR (IgEantibody receptor) cross-linking by allergen. EtOAc extract also can alleviate passive cutaneous anaphylaxis in mice [6]. The aforementioned observation implies that the components existing in EtOAc extract possess the inhibitory bility against type I hypersensitivity so called allergy. An anti-allergic compound called genistein 4'-O- $\beta$-D-glucoside 4"-Omethylate is further purified from the methanol extract of GSCM [7]. The anti-allergic capability of methyl-glycoside on $\beta$-hexosaminidase release is better than genistein or genistin, both of which are major isoflavones in most soy products and participate in the regulation of immune response. It also can inhibit the expression of IL-4 as well as TNF- $\alpha$ and FceR-provoked signaling cascade. In addition to anti-allergic effectiveness, a study in $70 \%$ ethanol extract (CME) of cultured $C$. militaris mycelia showed that CME treatment can scavenge DPPH, suggesting it possesses anti-oxidation capability. CME showed anti-inflammatory activity in the croton oilinduced ear edema and carrageen in-induced edema in mice [8]. Recently Hwang et al. (2016) reported that WIB801C, the cordycepin standardized extract of $C$. militaris, can reduce post-ischemia inflammation and improve neurological deficit. WIB801C treatment also can increase survival rate of rats with cerebral ischemic stroke via decreased infiltration of microglia/inflammatory cells, reduced infarct volume/cerebral edema and dwindled blood-brain barrier damages [9].

\section{Conclusion}

The incidences of allergy are steadily increasing in many developed countries in the past decades. Most of the existing therapies for allergic diseases will lead to uncomfortable side effects. Thus mycelia or fruit bodies of C. militarys may confer a resource for finding a target drug to cure or alleviate allergy. Although great efforts have been spent on finding a better way to cure or prevent cancers in the past century, it is still a long way to go. $C$. militaris may at the same time offer a complementary/integrative therapeutic source to prevent or treat various tumors.

\section{Acknowledgements}

This work was supported by the Ministry of Science and Technology of Taiwan (grant number MOST 1052320-B-218 -001-MY3).

\section{References}

1. Sung GH, Hywel Jones NL, Sung JM, Luangsa Ard JJ, Shrestha B, et al. (2007) Phylogenetic classification of Cordyceps and the clavicipitaceous fungi. Stud Mycol 57(1): 5-59.

2. Zhou X, Gong Z, Su Y, Lin J, Tang K (2009) Cordyceps fungi: natural products, pharmacological functions and developmental products. J PharmPharmacol 61(3): 279-291.

3. Mollah ML, Park DK, Park HJ (2012) Cordyceps militaris Grown on germinated soybean induces G2/M cell cycle arrest through downregulation of cyclin B1 and cdc25c in human colon cancer HT-29 Cells. Evid Based Complement Alternat Med: 249217.

4. Park SE, Yoo HS, Jin CY, Hong SH, Lee YW, et al. (2009) Induction of apoptosis and inhibition of telomerase activity in human lungcarcinoma cells by the water extract of Cordyceps militaris. Food ChemToxicol 47(7): 1667-1675.

5. Ruma IM, Putranto EW, Kondo E, Watanabe R, Saito K, et al. (2014) Extract of Cordycepsmilitaris inhibits angiogenesis and suppresses tumor growth of human malignant melanomacells. Int J Oncol 45(1): 209-218.

6. Oh JY, Choi WS, Lee CH, Park HJ (2011) The ethyl acetate extract of Cordycepsmilitaris inhibits IgEmediated allergic responses in mast cells and passive cutaneous anaphylaxis reaction in mice. J Ethnopharmacol 135(2): 422-429.

7. Park DK, Choi WS, Park HJ (2012) Antiallergic activity of novel isoflavonemethyl-glycosides from Cordyceps militaris grown on germinated soybeans in antigenstimulated mast cells. J Agric Food Chem 60(9): 230923015. 
8. Won SY, Park EH (2005) Anti-inflammatory and related pharmacological activities of cultured mycelia and fruiting bodies of Cordyceps militaris. J Ethnopharmacol 96(3): 555-561.
9. Hwang S, Cho GS, Ryu S, Kim HJ, Song HY, et al. (2016) Post-ischemic treatment of WIB801C, standardized Cordyceps extract, reduces cerebral ischemic injury via inhibition of inflammatory cell migration. J Ethnopharmacol 186: 169-180. 